\title{
Lasar Segall entre viagens e migraçōes: um europeu nos trópicos
}

\section{Mônica Raisa Schpun ${ }^{* * * *}$}

\section{Resumo}

Neste artigo, examino os deslocamentos migratórios do artista plástico Lasar Segall (1889-1957). Trata-se, a meu ver, de um caso paradigmático para o estudo das migrações de artistas tanto pelas marcas deixadas pela experiência migratória em sua pintura, quanto pelo destaque a elas dado na recepção crítica de sua obra. Nesse exercício, abordo as especificidades das migrações do artista dentro de um contexto mais amplo de fluxos migratórios contemporâneos aos seus. De fato, o período mais movimentado da vida de Segall, de 1906 a 1932, entre viagens e migrações, também foi marcado por grandes fluxos migratórios tanto intraeuropeus como transatlânticos. Enfim, alguns temas conexos também serão tratados, como nacionalismo, xenofobia e racismo, cosmopolitismo, exotismo, transnacionalismo e exílio.

Palavras-chave: Lasar Segall, Viagens, Migrações, Recepção crítica, Europa, Brasil

* Centre de recherches sur le Brésil colonial et contemporain/Mondes américains - EHESS, Paris, França / ** Faculdade de Arquitetura e Urbanismo - Universidade de São Paulo, São Paulo-SP, Brasil. 


\section{Lasar Segall between travels and migrations: a European in the tropics}

\section{Abstract}

In this article, I examine the migrations of the plastic artist Lasar Segall (18891957). In my view, this constitutes a paradigmatic case for the study of migrations of artists both for the imprints left by the migration experiences on his painting, and for the prominence attributed to them by the critical reception of his work. In this exercise, I consider the specificities of the artist's migrations within a broader context of migration flows contemporary with his own. In fact, Segall's busiest period, from 1906 to 1932, between travels and migrations, was also marked by large intra-European and transatlantic migration flows. Finally, some related themes will also be treated, such as nationalism, xenophobia and racism, cosmopolitanism, exoticism, transnationalism and exile.

Keywords: Lasar Segall, Travel, Migrations, Critical reception, Europe, Brazil

S migrações de artistas são estudadas, no mais das vezes, sob o
prisma das migrações voluntárias, ou "consentidas" (Gouzi, 2016).
Entretanto, ainda que os deslocamentos sejam voluntariamente decididos e mesmo planejados, enfrentam ou suscitam o involuntário, o imprevisível, aquilo que se dissocia ou escapa dos projetos conscientemente estabelecidos pelos artistas em questão. Os deslocamentos migratórios, sejam eles definitivos ou transitórios, mais ou menos longos, únicos ou múltiplos, circulares ou pendulares, decididos de forma voluntária - como no caso das viagens de formação -, ou constrangida - como no caso dos exílios -, trazem aos seus protagonistas desafios imprevistos, pelos encontros e desencontros que provocam e promovem. A migração é, vale sublinhar, uma viagem sem duração fixa e que se abre fortemente ao imprevisto, expondo de modo particular os atores sociais a obstáculos de outro modo inexistentes.

Assumindo, assim, um registro de história das migrações - e afastandome de um recorte ligado à história da arte -, examinarei, nas páginas que seguem, os deslocamentos migratórios de Lasar Segall (1889-1957). Trata-se, a meu ver, de um caso paradigmático para o estudo das migrações de artistas 
tanto pelas marcas deixadas pela experiência migratória em sua pintura, quanto pelo destaque a elas dado na recepção crítica de sua obra. Nesse exercício, abordarei as especificidades das migrações do artista dentro de um contexto mais amplo de fluxos migratórios contemporâneos aos seus. De fato, o período mais movimentado da vida de Segall, entre 1906 e 1932, também foi marcado por grandes fluxos migratórios tanto intraeuropeus como transatlânticos. Se, em 1937, Segall voltou ao velho continente, os deslocamentos longos e/ou frequentes que marcaram sua vida até então não tiveram mais continuidade, por conta do novo e dramático contexto em que mergulhara a Alemanha - e a Europa. O artista não deixou, entretanto - e absolutamente -, de alcançar e tematizar, com seus pincéis, a experiência de massas de europeus ainda em movimento no final dos anos de 1930, que o interpelava diretamente. Assim, ao examinarmos sua carreira sob uma perspectiva de estudos migratórios, observa-se que essa se construiu por meio e no decurso de seus deslocamentos, jogando de um lado e de outro do Atlântico com os recursos - sociais, culturais, profissionais e plásticos - tirados de cada margem. Formado na Europa, mesclou, segundo os diferentes momentos de seu itinerário, motivos e cores de inspiração diversa, respondendo a expectativas, debates e cânones europeus, mas também, ao inserir-se na sociedade brasileira - e particularmente no seio de suas elites artísticas e culturais -, aos debates e embates desta. Empregou, assim, sua agência pessoal, para beneficiar-se das situações de transnacionalismo vividas, nas quais, de um lado do Atlântico, não perdia de vista a outra margem. Em trânsito, confrontou-se com as sobredeterminações históricas impostas em variados contextos, mas também com as vozes dos atores responsáveis por sua recepção. Quanto a estes, concentrar-me-ei aqui nos dois críticos, raramente mencionados, que escreveram sobre Segall na França, e no nome mais importante de sua recepção no Brasil, Mário de Andrade'1.

1 Este artigo é uma versão bastante modificada e aumentada de outro, publicado em francês (Schpun, 2009). Uma versão prévia foi apresentada no Simpósio "Imigração e raça no Brasil: diálogos interdisciplinares" (FFLCH-USP, 8-9 de agosto de 2016). Agradeço a Paulo César Garcez Marins pela leitura atenta. 


\section{Um cosmopolita face às fronteiras europeias}

Lasar Segall nasceu em 1889 em Vilna, àquela época pertencente ao Império Russo, em uma família judia. Em 1906, com 17 anos, deixou seu país natal a fim de prosseguir uma formação artística iniciada no ano anterior. Instalando-se na Alemanha, inscreveu-se na Escola de Artes Aplicadas de Berlim e, em seguida, na Academia de Belas Artes. Em 1910, mudou-se para Dresden e passou a frequentar a Academia de Belas Artes da cidade ${ }^{2}$. No final de 1912, embarcou para o Brasil, a convite de sua irmã Luba que, com mais dois irmãos do pintor, já vivia no país. Com a intenção inicial de fixar-se no país (Mattos, 2000), o artista acabou permanecendo aqui por apenas oito meses, antes de retornar a Dresden.

Na época, uma pequena comunidade judaica já existia em São Paulo, cidade para onde se dirigiu o pintor. Esta era majoritariamente formada por judeus do leste europeu que, como os Segall, tinham o ídiche como língua comum, em um universo marcado pelo multilinguismo (russo, ucraniano, polonês etc.). Os membros do grupo eram, em geral, pequenos artesãos e comerciantes, muitos dos quais ambulantes. Distinguindo-se da maioria, os Segall, junto com outras poucas famílias, compunham então a elite da comunidade. Luba Segall, em particular, era casada com um membro da família Klabin, de industriais já estabelecidos no ramo do papel, quando da chegada do jovem Lasar. Intelectualizados e sensíveis ao mundo das artes, os membros desse pequeno núcleo estavam inseridos em redes sociais não exclusivamente judaicas, fato digno de nota.

Ao que tudo indica, o pintor não apreciou suficientemente sua estada na então provinciana São Paulo, para prosseguir em seu projeto migratório inicial. De fato, a cidade não contava, na época, com um mercado de artes estruturado, não dispondo de galerias nem de museus; dependia-se do gosto e do interesse de colecionadores ainda pouco numerosos e, no mais das vezes, reticentes às novas tendências artísticas. Apesar disso, graças às

${ }^{2}$ As informações biográficas sobre Lasar Segall apresentadas a seguir foram tiradas de Beccari (1984) e Mattos (1997, 2000, 2007). 
redes de conhecimento mobilizadas por sua irmã, em meio às elites locais, o pintor fez conferências, expôs e vendeu quadros. Luba introduziu Lasar ao mecenas e colecionador José de Freitas Valle, proprietário da Villa Kyrial, ponto chave da vida mundana e cultural na São Paulo da Belle Époque. Freitas Valle não somente financiou a exposição paulistana de Segall, como adquiriu três obras do artista: "Sem recursos", "Auto-retrato" e "Menino da Suíça Saxônica" (ou "Tipos holandeses (c)"). No total, graças às redes mobilizadas, o artista vendeu, nas duas exposições feitas em 1913, em São Paulo e em Campinas, 21 obras (Beccari, 1984).

Mas voltemos um pouco atrás. Antes dessa primeira viagem ao Brasil, Segall estudara na Academia de Dresden de dezembro de 1910 até março de 1912. A partir dessa data, "trancou sua matrícula" de modo quase contínuo até o outono (europeu) de 1914³. Foi então que, com o início da guerra, viu-se privado do direito de frequentar a instituição, por ser cidadão russo, "inimigo da nação alemã" (Mattos, 2000, p. 33). Contrariamente a outros artistas russos que também viviam na Alemanha, Segall não foi confinado na cidade de Meissen: com a ajuda de um professor da Academia, obteve uma autorização que lhe permitiu permanecer em Dresden (Mattos, 2000; Beccari, 1984). Mesmo assim, sem poder frequentar a Academia e dispor, como antes, de um ateliê para trabalhar, seus horizontes se estreitaram, enfrentando um período difícil, inclusive financeiramente.

No contexto da guerra, os artistas judeus russos, como Segall e seus amigos, eram pró-alemães. Apesar de terem sido tratados com desconfiança, e confinados, não representavam qualquer ameaça política ao país que os acolhia. De fato, o Império Russo era, na época, palco de violentas perseguições antissemitas, o que eliminava qualquer possibilidade de identificação desses imigrantes com seu país natal. A Alemanha, por sua vez, dentre os grandes países europeus, era aquele em que os judeus viviam sob maior tolerância: a França era então o país do caso Dreyfus, ao passo que a

${ }^{3}$ Segundo Mattos (2000), que reviu a cronologia geralmente aceita para esse período da formação do pintor (narrada por ele próprio em suas memórias), Segall teria frequentado a Academia durante alguns meses, em 1914, durante os quais dispôs da vantagem de ter um ateliê para trabalhar e de "liberdade artística". 
Inglaterra impusera, já em 1900, estritas limitações à imigração judaica (Elon, 2002). Esse contexto favorável não significava, contudo, que os judeus alemães gozassem de uma cidadania plena em seu país. Nesse sentido, o grupo de artistas não recebeu com entusiasmo o aumento do fluxo de judeus vindo do Império Russo, temendo serem identificados com os recém-chegados, mais religiosos, falantes de ídiche (que os alemães abandonaram décadas antes, em benefício da língua nacional) e cujos homens, com suas longas barbas, diferenciavam-se dos demais cidadãos no espaço público (contrariamente aos alemães, que já as tinham cortado há muito). O resultado de várias décadas de integração parecia ameaçado por essa nova e numerosa presença. Uma das atitudes tomadas pelas lideranças judaicas alemãs, frente a esse novo fluxo, foi a de proporcionar ajuda e assistência aos recém-chegados facilitando-lhes a reemigração em direção às Américas. Evitavam, assim, uma presença e uma visibilidade por demais importantes no espaço público, capazes de despertar o antissemitismo de seus compatriotas (Elon, 2002) ${ }^{4}$.

Não temos como saber se esse importante movimento migratório e as tensões que pôde ter gerado interessavam ou afetavam de algum modo Segall, sendo tema de conversas e reflexões com seus colegas e amigos do mundo das artes. Esses compunham uma fração extremamente minoritária dos imigrantes fugindo dos pogroms que varriam a Zona de Residência judaica demarcada no Império Russo; viviam uma experiência migratória particular, apesar do passaporte e da pertença judaica comuns aos demais imigrantes. Sabemos, porém, que Segall manteve-se sempre interessado pelos debates e reflexões envolvendo a construção de uma "arte judaica" (Mattos, 2007).

O isolamento e o aperto financeiro de Segall duraram do final de 1914 até meados de 1916, quando o pintor se instalou na casa do mecenas judeu Victor Rubin, amigo de sua família, que passou a ajudá-lo; foi na casa de Rubin que tomou contato com os artistas de vanguarda da cidade, passando

${ }^{4}$ Mais de dois milhões de judeus deixaram o Império Russo entre 1880 e 1914, majoritariamente em direção aos Estados Unidos (Schpun, 2011). Nesse país, os judeus orientais também foram recebidos pelos judeus alemães, que imigraram mais cedo, em meados do século XIX, e dirigiam grande parte das associações judaicas na época. Como na Alemanha, tal chegada não foi festejada, tendo sido percebida como uma ameaça a uma cidadania ainda frágil e incompleta (cf. Johnson, 2005). 
a incorporar elementos cubo-futuristas em sua obra (Mattos, 2000). Sob a influência desse novo meio, sua obra sofreu uma grande transformação entre 1916 e 1918: simplificação geométrica das figuras, que se tornaram mais esquemáticas, recurso à abstração e valorização da superfície da tela, em detrimento da perspectiva, que passou a evitar (Mattos, 2000). Sua conversão ao expressionismo deu-se nesse período.

Em 1918, com o fim da guerra, Segall pôde viajar novamente para fora da Alemanha, recuperando uma liberdade maior de movimentos. Voltou, então, a Vilna para visitar a família, ali permanecendo por quatro meses. $\mathrm{Na}$ época, o movimento artístico pela arte nacional judaica ganhara força, por conta do influxo de liberdade que se seguiu à Revolução de $1917^{5}$. Em Vilna, Segall tomou contato com membros do movimento, então em plena efervescência, e com seus avanços e reflexões. Isso se deu em um momento em que já se encontrava plenamente integrado ao movimento expressionista de Dresden.

Esse encontro causou "um grande impacto sobre a obra de Lasar Segall" (Mattos, 2007, p. 86): além de explorar de modo intenso temas judaicos naquilo que passou então a produzir, o artista transformou completamente sua paleta, com a adoção de cores sóbrias e a exploração de tons e degradés delas derivados (Mattos, 2007, p. 88). Com isso, Segall aderia a alguns dos princípios adotados pelos artistas engajados na construção de uma arte

${ }^{5}$ Os artistas russos comprometidos com o "Renascimento Judaico" aspiravam pela construção de uma arte nacional judaica. O movimento tomou forma no final do século XIX, período marcado por um antissemitismo virulento no Império Russo. A busca de uma arte judaica acompanhou a emancipação política dos judeus e emergiu com força no início do século XX: em 1902, foi criado o Círculo dos Artistas Judeus e, em 1908, a Sociedade Histórica e Etnográfica Judaica, ambas em São Petersburgo. Esta última tinha como objetivo a busca de documentação sobre as práticas e o folclore judaico. Entre 1912 e 1914, ela promoveu uma grande expedição através da Zona de Residência do Império, da qual participaram alguns artistas que fotografaram e copiaram motivos presentes nas sinagogas e sepulturas; uma segunda expedição ocorreu em 1916. Nesse ano, foi criada, ainda, a Sociedade para o Encorajamento da Arte Judaica, que organizou uma exposição de arte judaica. O vento de liberdade trazido pela Revolução de Outubro deu maior visibilidade aos artistas judeus, promotores de outros grupos, organizações e eventos em diversas cidades russas. Muitos deles, que compunham uma geração mais jovem, como Rybak, Lissitzky e Chagall, exploravam motivos judaicos empregando uma linguagem moderna de vanguarda. Essa curta explosão de liberdade durou até os primeiros anos da década de 1920, apagando-se em seguida (Le Foll, 2002). 
nacional judaica. De fato, em um artigo publicado em 1919 por dois nomes particularmente envolvidos com o movimento, Issachar Ryback e Boris Aronson, estes defendiam a ideia de que os artistas judeus, diferentemente dos demais, russos, tendiam a privilegiar a superfície, em vez da profundidade e do volume, e a valorizar as cores impuras e sóbrias, a variação de tons, em vez das cores puras ${ }^{6}$. Segall pintou, justamente naquele momento, quadros de grande força pictórica (como "Kaddish", de 1918, "Eternos Caminhantes", de 1919, e "A Gestante", de 1920), responsáveis por seu reconhecimento em âmbito nacional na Alemanha. Nestes, explorou as cores tidas como "tipicamente judaicas": violeta, ocre, cinza e ouro (Mattos, 2007, p. 89).

Paradoxalmente, o sucesso alemão de Segall deu-se, nesse imediato pós-guerra, em um contexto de crescente nacionalismo, xenofobia e antissemitismo no país, ao qual se acrescentava uma crise econômica sem precedentes. A humilhação imposta à Alemanha pelo Tratado de Versalhes trouxe, de fato, consequências gravíssimas para a economia - e para a situação dos judeus ${ }^{7}$. Na época, os expressionistas alemães adotavam posições políticas cada vez mais nacionalistas, opostas à postura irredutivelmente cosmopolita defendida por Segall, barreira maior, aliás, para sua adesão ao movimento pela arte nacional judaica, que jamais integrou completamente. Para ele, o caminho melhor para os artistas judeus seria

6 "Os caminhos da arte judaica", publicado em ídiche ("Di Wege fun der Jüddischer Malerei") na revista Oifgang. Cf. Mattos (2007, p. 87-8). Ver ainda, sobre outros aspectos desse texto importante para a reflexão do movimento em questão, Le Foll (2002).

7 Segundo Gershom Scholem (1991, p. 41-2), que deixou a Alemanha em 1923 (com 26 anos de idade), instalando-se na Palestina, "[a] esperança [da parte dos judeus] de uma emancipação social que deveria seguir a emancipação política, concluída entre 1867 e 1870, e em parte a esperança de diluir-se no seio do povo alemão [...] estavam em aberta contradição com a experiência generalizada de um anti-semitismo em expansão, uma experiência à qual só era possível escapar num plano meramente imaginário". O autor traz vários exemplos para apoiar sua opinião de que os judeus alemães teriam se recusado a enfrentar uma situação que não nasceu em 1933. Um deles é a declaração do respeitado Werner Sombart, em 1912, de que "a equiparação e a emancipação dos judeus perante a lei não deviam ser revogadas formalmente, só que os judeus, de livre e espontânea vontade, não deveriam fazer uso desses direitos, sobretudo na vida pública" (Id., p. 43). Em Munique, onde Scholem viveu de 1919 a 1922, "presenci[ou] o surgimento do nacional-socialismo na universidade. O ambiente na cidade era insuportável [...]. Mas era terrível notar a cegueira dos judeus que não queriam saber de nada, não queriam enxergar nada" (Ibid., p. 151). 
o da integração à arte e à cultura ocidentais. O pintor acreditava, contudo (como os artistas judeus envolvidos com o "Renascimento Judaico"), na existência de uma "natureza" dos judeus - e dos artistas judeus - que, sendo "naturalmente" introspectivos, encontravam-se mais próximos da arte expressionista. Mas sempre em um sentido universalista e universalizante: essa "natureza" dos judeus funcionava, a seu ver, como um facilitador para a expressão universal buscada. Assim, contrário a qualquer particularismo - alemão, judaico ou outro -, mantinha-se alheio a toda expressão ou intenção de cunho nacionalista, qualquer que fosse sua origem. Tudo isso não o poupou de ser identificado, na Alemanha, como artista judeu, russo, oriental, bases de um sucesso que seguiu vias diversas daquelas às quais aspirava. Como bem demonstrou Mattos (2000, p. 186), no momento em que Segall se firmava enquanto expressionista alemão, a crítica já considerava “a questão nacional um tema de importância central, vendo em Segall essencialmente um representante de outra nação e 'raça' (russo e judeu)" ${ }^{\prime 8}$.

Durante todos aqueles anos, Segall permaneceu informado sobre a situação brasileira, e particularmente paulistana, graças à correspondência trocada com a família, e sobretudo com a irmã Luba, que já o recebera em 1913. O pintor sabia, então, que a cidade estava mudando rápida e intensamente - e que o modernismo trouxera novidades ao mundo das artes. Assim, vivendo em um contexto marcado, ao mesmo tempo, por sua excelente recepção crítica na Alemanha e pela aguda crise financeira que redundara no esgotamento do mercado de artes (para viver, contava então com a ajuda financeira de Victor Rubin e da irmã Luba), além do forte nacionalismo e antissemitismo, Segall acabou repensando o Brasil como alternativa de vida. E, no final de 1923, após ter voltado a se instalar em Berlim, deixou o país com sua esposa Margarete Quack, rumo a São Paulo. Detinha, dessa vez, uma sólida bagagem enquanto artista plástico, com nome já reconhecido na Alemanha, o que se exprimia, inclusive, pela presença de obras suas em coleções de museus do país. Isso não deixou de

${ }^{8}$ Grifo da autora. 
chamar a atenção da fração das elites locais ligada aos artistas "modernos", ávida de cosmopolitismo e de modernidade.

Desta feita, sua intenção era diametralmente oposta àquela da primeira viagem, quando, apesar de ter pensado em se instalar definitivamente em São Paulo, dera meia-volta. Em 1923, Segall planejava se afastar temporariamente da Alemanha (Mattos, 2000). Tratava-se, assim, de um investimento visando, pelo deslocamento migratório, alavancar provisoriamente sua carreira além do Equador.

O dispositivo é digno de nota em termos de práticas migratórias: Segall buscava alçar-se na carreira artística graças a um investimento de deslocamento internacional, evitando o estancamento. Tal estratégia de reconversão era, no fundo, bastante corrente, e não exclusivamente entre artistas: assim agindo, os atores sociais procuravam ganhar trunfos profissionais no exterior esperando superar, em seguida, obstáculos enfrentados localmente. No que toca ao período das grandes migrações transatlânticas, Schniedewind (1993) descreveu essa prática entre os numerosos empregados do comércio de Bremen, que foi, juntamente com a cidade satélite de Bremerhaven, o principal porto de emigração na Alemanha do século XIX. O paralelo é pertinente quando pensamos, para a virada dos séculos XIX-XX, no intenso movimento migratório de artistas através do Atlântico, rumo à Europa, e dentro do continente europeu. Com efeito, os artistas exploraram intensivamente tal estratégia, em viagens, mais ou menos longas e repetidas, de formação, e em percursos migratórios que seguiram traçados os mais variados, em espaços e períodos também amplos e diversos. Nesse exercício de transnacionalismo, investiram, simultaneamente ou consecutivamente, em mais de um espaço. Usufruíram, assim, dos recursos disponíveis, nem sempre acessíveis sem essa experiência, e fizeram-nos frutificar alhures.

Segall deixou a Alemanha com a reputação em alta, apesar das dificuldades materiais enfrentadas. No seu caso, a migração não significou, contudo, a perda do prestígio acumulado no país de origem; o trajeto de seu deslocamento, da Europa para o Brasil, era-lhe, enquanto artista já maduro, vantajoso. Assim, sua recepção no Brasil recolocou os ponteiros 
no lugar: aportando aqui como um artista completo, ocupou sem demora uma posição de destaque e liderança no meio que o recebia. Para além da reputada qualidade de sua pintura e das facilidades advindas das redes de relações disponibilizadas por sua irmã, a bagagem profissional acumulada na Europa trouxe-lhe, em um país que tradicionalmente valoriza o novo e o de fora, vantagens imediatas (Sorj, 1997).

Entretanto, experiências migratórias trazem sempre desafios desconhecidos. A troca de contextos socioeconômicos, políticos e artístico-culturais apresenta obrigatoriamente uma dose não desprezível de incertezas e imprevistos. $\mathrm{E}$ Segall não foi poupado disso: em 1924, poucos meses após sua chegada, o pintor separou-se de Margarete, que retornou sozinha à Alemanha. Ele, então, casou-se (religiosamente) com Jenny Klabin, cunhada de sua irmã Luba. Não é raro, com efeito, que projetos migratórios inicialmente pensados como "temporários" (ou "definitivos") sejam em seguida reavaliados e transformados diante da realidade encontrada no país de destino - o que embaralha e derruba categorias classificatórias, tornando os percursos mais complexos.

Nos anos seguintes, apesar do enraizamento local que o novo casamento sinalizava, o irrequieto Segall seguiu movendo-se entre o Brasil e a Europa. Em 1926, voltou - temporariamente - à Alemanha, para cuidar do divórcio com Margarete. Expôs, então, em Berlim e em Dresden, além de obras mais antigas, as primeiras produções da sua fase brasileira ${ }^{9}$. De volta ao

${ }^{9}$ Em Berlim, de um total de 54 óleos sobre tela expostos, 16 datavam de 1924-26, tendo sido pintados no Brasil: "Homem Velho" (1924), "Encontro" (1924), "Dama no Café" (1924, obra desaparecida), "Mulata com Criança" (1924), "Menino com Lagartixa" (1924), "Cega com violão" (1924), "Natureza Morta" (1924), "Marinheiro Negro" (1924, obra desaparecida), "Mulato I" (1924), "Casal de Negros Brasileiros" (1925), "Judeu Sentado" (1925), "Paisagem Brasileira" (1925, identificação provável), "Judeu Orando" (1925), "Morro Vermelho" (1926), "Gestante III" (1926, retrato da esposa Jenny então grávida) e "Pensão Nenette" (1926, obra que o pintor "apagou", pintando na mesma tela, em 1956, "Rua de Erradias I"). Das oito aquarelas expostas, uma fora pintada em 1924: "Esboço de Retrato. R. B." (provavelmente a obra "Rebeca", um retrato de Rebeca Bessel). As 64 obras gráficas expostas foram realizadas antes de 1924, ainda na Alemanha (Cf. Schmidt; Segall, 1926). Em Dresden, a exposição compreendeu menos obras. Dentre aquelas realizadas no Brasil, o artista escolheu parte dos óleos sobre tela indicados acima: "Encontro" (1924), "Dama no Café" (1924), "Mulata com Criança" (1924), "Natureza Morta" (1924), "Mulato I" (1924), "Casal de Negros Brasileiros" (1925), "Judeu Sentado" (1925), "Paisagem Brasileira" (1925, identificação provável), "Morro Vermelho" (1926), "Gestante III" (1926) e "Pensão 
Brasil, não se demorou muito no país: já naturalizado, partiu novamente para a Europa, em 1928, dessa vez para Paris, onde tentou se reintegrar de modo mais duradouro ao meio artístico europeu ${ }^{\mathbf{1 0}}$.

Naqueles anos, vale dizer, ainda que os fluxos migratórios de europeus em direção ao Brasil tivessem diminuído muito, a Europa ainda era um continente de emigração e o Brasil, de imigração ${ }^{11}$. Os deslocamentos no sentido contrário, como os de Segall, constituem uma especificidade dos deslocamentos de artistas. A Europa, e Paris em particular, atraía artistas em viagens de formação, mas também imigrantes que ali se instalavam, integrando a cosmopolita geração da chamada "Escola de Paris".

Na capital francesa, Segall pôde explorar, além das suas próprias, as redes de conhecimentos criadas e desenvolvidas por seus novos amigos brasileiros, principalmente Tarsila do Amaral e Oswald de Andrade, membros das elites artísticas e culturais em meio às quais se inserira de modo extremamente rápido. Contatou efetivamente Blaise Cendrars e o marchand e galerista Léonce Rosenberg, ambos conhecidos do casal modernista. Porém, diferentemente de Tarsila do Amaral, que, em Paris, frequentou ateliês de mestres e se formou enquanto pintora "moderna", esse deslocamento de Segall não tinha nada de uma viagem de formação; o artista já dispunha, na época, de vasta produção e reconhecimento. De fato, ele podia valer-se, ao se apresentar, de uma produção artística que, com sólidas bases expressionistas, tratara também, a partir de 1924, motivos

Nenette" (1926) Cf. carta de Lasar Segall ao Sr. Probst (Dresden), manuscrito em alemão (coleção Museu Lasar Segall). Nessa carta, Segall pede a seu correspondente que, depois da exposição, envie três dessas obras para Stuttgart, onde deveria expô-las também. Não existe registro da existência dessa última exposição, que pode não ter acontecido. Agradeço a Pierina Camargo e Daniel Rincon Caires do Setor de Pesquisa do Museu Lasar Segall que me receberam e identificaram para mim as obras listadas aqui. Daniel Caires traduziu os títulos do alemão, indicando aqueles pelos quais as obras são conhecidas hoje; traduziu também a carta de Segall a Probst, com instruções sobre as obras enviadas a Dresden.

${ }^{10}$ As importantes reformas às quais submeteu seu apartamento de Montparnasse, onde instalou um ateliê em duplex, desvelam essa intenção (cf. cartas de Lasar Segall a seu agente imobiliário e à empresa encarregada das reformas, acervo do Arquivo Lasar Segall). Vale notar aqui que sua nova situação financeira, trazida pelo segundo casamento, contrastava com as dificuldades enfrentadas na Alemanha antes de 1923.

11 O país vivia, então, o período mais frutuoso quanto às entradas de japoneses (1926-1934). 
e cores tropicais. E valeu-se, nessa volta à Europa, de suas experiências migratórias anteriores: com a nova produção brasileira, operou uma espécie de restituição europeia da passagem pelos trópicos. Tratava-se, de certo modo, de um retorno às origens, pois o artista não se limitou aos contatos franceses dos amigos brasileiros, muito pelo contrário. Em 1930, por exemplo, recebeu em Paris o diretor do Museu de Breslau, Erich Wiese, que adquiriu gravuras com motivos brasileiros para a coleção do museu ${ }^{12}$.

Entretanto, seja porque o pintor não encontrou em Paris as possibilidades almejadas de integração ao meio artístico francês e, mais geralmente, europeu, seja porque os vínculos familiares no Brasil tomaram a dianteira, ou por um misto de ambos, a família atravessou novamente o Atlântico, retornando aos trópicos em 1932, depois de quase quatro anos de ausência. Os deslocamentos de Segall, até ali tão frequentes, tornar-se-iam doravante raros: o contexto europeu estava perto de se transformar radicalmente; para um artista judeu, viver no Brasil, ganharia então vantagens consideráveis.

\section{Um artista "universal" na rota transatlântica}

A longa passagem de Segall por Paris, apesar de pouco (ou nunca) estudada, deixou vestígios significativos. Em 1931, ele expôs na galeria

\footnotetext{
12 Não é possível identificar exatamente quais foram as obras compradas nessa ocasião. De um lado, os registros de Segall se interromperam justamente no momento em que essa aquisição seria anotada (a última inscrição feita pelo pintor limitou-se à menção "Besitz Museum Breslau", sem outra precisão). De outro lado, os nazistas confiscaram um número importante de suas obras, em vários museus do país (58, segundo registros atuais, majoritariamente gravuras). Muitas delas ainda se encontram sem paradeiro conhecido, algumas sem identificação precisa e somente duas foram restituídas aos museus de origem. Cartas de Erich Wiese a Lasar Segall, datadas de 1930-31, indicam que Wiese efetivamente visitou Segall em Paris e comprou gravuras para o museu, mas não há menção aos títulos das obras adquiridas. Daniel Rincon Caires identificou 19 obras do artista que faziam parte da coleção do Museu de Breslau e foram confiscadas pelos nazistas no contexto da "Ação contra a Arte Degenerada". Agradeço a Daniel Rincon Caires que me comunicou esse levantamento e uma parte de sua dissertação de mestrado em curso, com referências às cartas de Wiese ao pintor (acervo do Arquivo Lasar Segall). Cf. Caires (2018).
} 
Vignon ${ }^{13}$ e o crítico Waldemar George ${ }^{14}$ dedicou-lhe uma monografia muito elogiosa (George, 1931). Ele parecia conferir uma grande importância ao artista: "[e]sta é a história de um pintor cuja obra resume todas as tribulações da arte contemporânea" (George, 1931, p. 7; traduções minhas). E lançou um olhar ao mesmo tempo original e perspicaz sobre essa primeira produção brasileira de Segall:

[...] Na sua chegada ao Brasil o artista é atraído pelo caráter exótico do país. Ele põe em relevo seu aspecto pitoresco. Ele o ilustra. [...] Ele não despreza nem a charge, nem a caricatura.

[...] Uma paleta simplificada. [...] A paz reina nessas obras. Uma cadência calma e grave convém aos seres felizes que se movem nas telas de Segall. De início, um toque de ironia se mescla às interpretações que o pintor produz da América do Sul. Antes de compreender e de aprender a amar este estranho continente, ele o examina com curiosidade. Parece que ele se diverte. [...] Esta arte, ao mesmo tempo ingênua [naïve], convencional e tão cheia de imprevistos, age sobre nós como uma fonte de juventude. O próprio artista sai rejuvenescido deste convite. O contato da terra e o contato dos homens que falam com seus corpos o regenera, o liberta, o transforma (George, 1931, p. 14-7).

Após chegar ao Brasil, em 1924, Segall substituiu imediatamente a paleta alemã, que explorava tons de ocre, cinza e violeta e o trabalho com os dégradés, por cores puras e contrastantes, evocando uma luminosidade tropical. Os motivos também mudaram, com a introdução em profusão da vegetação tropical e das personagens negras, protagonistas de boa parte das obras da época - inclusive de autorretratos em que o pintor representa a si mesmo como negro, radicalizando a poesia encontrada na nova terra.

${ }^{13}$ A galeria pertencia à colecionadora Marie Cuttoli (1879-1973), próxima de vários artistas da "Escola de Paris", mas também, entre outros, de Fernand Léger, com quem Tarsila do Amaral estudara. O catálogo da exposição foi prefaciado por Paul Fierens.

${ }^{14}$ Jerzy Waldemar Jarocinski, conhecido como Waldemar George (1893-1970), nasceu em Lodz, na Polônia, em uma família judia. Instalando-se na França, em 1911, tornou-se rapidamente um dos críticos de arte mais influentes do entre guerras, tendo seu nome ligado à "Escola de Paris", da qual foi um dos promotores (Chevrefils Desbiolles, 2008). 
As representações de rostos e corpos africanos eram-lhe familiares graças à valorização da arte africana na Alemanha do início do século XX. Alguns livros de sua biblioteca demonstram seu interesse pela estatuária africana, que também estava presente nas coleções de museus alemães que ele pôde visitar antes da partida para o Brasil. Em muitos dos seus quadros e gravuras, os rostos das personagens negras lembram diretamente essa estatuária (D’Alessandro, 2000). Apesar desse filtro pictórico forte advindo da Alemanha, no Brasil, graças às suas novas relações, Segall viu negros, antigos escravos e seus descendentes, modelos vivos que, mesclando-se à bagagem europeia, passaram (também) a compor seu arsenal imagético. Vale lembrar que tais representações não eram, de modo algum, correntes no Brasil. Em 1923, ao pintar "A Negra", em Paris, Tarsila do Amaral reagia - e integrava-se - à onda primitivista francesa, aderindo à valorização local desses motivos que no Brasil eram desprezados. A obra foi exposta na cidade-luz, em 1926, sem ter tido repercussão imediata no Brasil. Nesse sentido, a profusão de representações com negros em meio à vegetação tropical, assinadas por Segall entre 1924 e 1927, distingue-se claramente da produção artística brasileira do momento.

Ao escrever sobre essa produção de Segall, o crítico Waldemar George não conhecia o tecido social no qual o pintor passou a circular desde que se instalou no Brasil, limitando-se a imaginar o que ali existia. Para tal, ele dispunha de duas fontes principais. Em primeiro lugar, do imaginário que carregava sobre os trópicos, provavelmente muito próximo daquele do próprio pintor antes de seus deslocamentos transatlânticos. Além disso, nutria-se dos próprios quadros de Segall, visto como um tradutor sensível desse "estranho continente" onde, acreditava, os homens "fala[va]m com seus corpos". Para o crítico, apesar do caráter "pitoresco" das obras produzidas, nesse encontro entre Segall e os trópicos, ele seguia mestre, possuidor das ferramentas que lhe permitiam manter a distância que a "ironia" exige para se manifestar. Foi, aliás, com essa ideia que concluiu sua monografia, resgatando definitivamente o pintor: 
Segall chega na França com a plena posse de suas capacidades plásticas. Ele ainda carrega consigo as marcas da América. Todos os perfumes do Atlântico Sul planam sobre suas obras de uma secura sensual. Seus modelos são seres elementares e belos. [...]

O que sobrará na França deste sonho exótico? [...]

[Segall] só pode contaminar a Europa, asiatizá-la, corrompe-la, seduzi-la após ter bebido em suas fontes. Assim, é pela Europa que um dia ele chegará a este conhecimento íntimo do mundo e de si mesmo, este senso do equilíbrio e das justas proporções, este contato direto com a vida, que asseguraram à arte europeia sua vitalidade e sua continuidade. Segall não é um pintor vencido que volta ao seu lugar depois de uma rápida escapada [...]. A vitória que ele conquista sobre si mesmo é uma vitória moral por conta da Europa, que representa não uma parte do mundo, mas um estado de civilização. Lasar Segall atinge esse estado após de ter cumprido um longo périplo. Ele sacrifica todo provincialismo, todo judaísmo, todo americanismo às normas europeias, [...] as únicas que constituem uma garantia de universalidade (George, 1931, p. 18-9).

Já antes de Waldemar George, as consequências artísticas dos deslocamentos migratórios que marcaram o itinerário de Segall foram sublinhadas por outros críticos. Se George escreveu um texto significativo sobre o pintor, em um momento não menos significativo de sua carreira, e fora do eixo alemão, no qual era mais conhecido, outros seguiram sua obra de modo duradouro, como o fez, do Brasil, Mário de Andrade (18931945), nome-chave para a recepção do artista em São Paulo e no Brasil.

Diferentemente da maioria dos modernistas, Andrade não privilegiava a França no contexto artístico internacional, sentindo-se particularmente atraído pelas vanguardas alemãs. Conhecia bem o expressionismo, movimento pelo qual nutria verdadeira simpatia. Examinando sua biblioteca, Telê Porto Ancona Lopez (Lopez, 1991) encontrou não somente vestígios de seu aprendizado do alemão, já em finais da década de 1910, mas também obras de autores expressionistas, em edições datadas de 1918 a 1922, além de revistas de arte alemãs cobrindo sobretudo os anos de 1920. Sobre essa aproximação, Lopez (1991, p. 37) afirmou: “Temendo o francesismo, aproximou-se dos alemães e descobriu uma cultura nova 
para ele, procurando entendê-la [...]. Leu, estudou muito. Revelou aos brasileiros a arte e a literatura alemãs contemporâneas [...]". Seu interesse pela cultura alemã despontou, também, em diversos momentos de sua obra, em pinceladas muitas vezes discretas. Em 1926, o escritor publicou uma antologia de poemas intitulada Losango cáqui ou afetos militares de mistura com os porquês de eu saber alemão (escrita em 1922-24). Para seu Macunaíma, o conhecimento da língua alemã foi capital, permitindo-lhe o estudo das lendas que estão na base da obra, repertoriadas por Theodor Koch-Grünberg. Enfim, no momento da chegada de Segall ao Brasil, Mário de Andrade trabalhava em Amar, verbo intransitivo, título no qual esse filo-germanismo faz-se mais presente. Lopez, que qualificou a obra de "romance expressionista", sublinhou tal traço no ensaio citado. Na trama reina, como protagonista, uma governanta alemã. Surpreendentemente, dada a riqueza de detalhes de seu texto, Lopez não fez qualquer menção ao encontro entre o escritor e o pintor expressionista que, de viajante, tornara-se imigrante. Trata-se de acontecimento marcante não somente quanto à simpatia de Andrade pela Alemanha, como para suas pesquisas de renovação artística. A presença de Lasar Segall em São Paulo a partir de 1924 foi, sem sombra de dúvidas, um presente para Mário de Andrade. Fato digno de nota, o primeiro artigo que este dedicou a Segall data de janeiro de 1924, imediatamente após o desembarque do pintor. O crítico explicitou então seu interesse e conhecimento prévio da obra do artista:

Há muito que eu seguia nas revistas e jornais esse interessantíssimo artista que é Lasar Segall, russo. Acompanhara-Ihe mesmo a evolução, do quase impressionismo (época de que Freitas Valle tem nas suas coleções excelente exemplar) até os últimos trabalhos [...] (Andrade, 1924).

Nos anos seguintes, Mário de Andrade acompanhou de perto as transformações pelas quais passou o trabalho do artista, à medida que evoluía, paralelamente, sua própria reflexão literária e crítica. Assim, em um texto de 1925, refletiu ao mesmo tempo sobre o papel de Segall na cena artística local, e o do Brasil em sua pintura. Foi aí que este duplo 
encontro - entre o pintor e o crítico de arte, entre o pintor e seu novo país de imigração - ganhou em densidade:

A profundeza concentradamente apaixonada e a dramaticidade humana das obras dele, veio contrastar violentamente com a alegria um pouco superficial e a vivacidade por demais analítica da nossa aristocracia espiritual tradicionalmente educada (e me parece que excessivamente) nas ideias e tendências da Europa Latina. [...] Não seria muito exagerado afirmar que foi graças a Lasar Segall que muitos dentre nós, latinos, tornamos a encontrar a nossa ingenuidade (Andrade, 1924).

Mas o Brasil também teria trazido muito ao pintor:

Por outro lado o contato com a terra solar do Brasil e com a nossa alegria, provocou em Lasar Segall um novo período de evolução que se caracteriza pela alegria da cor. [...] Lasar Segall evolucionou estupendamente nestes últimos tempos. Na sua obra tão trágica [...] essa tragicidade era provocada principalmente pela deformação plástica dos corpos [...] e pelo sombrio um pouco fácil do colorido. Ora, nas suas obras recentes [...] essas tendências evolucionaram e essa cor sombria desapareceu. [...] é toda uma paleta nova de cores claras e cômodas que ele emprega. Sem nunca abandonar o essencial expressivo no qual suavemente agora transparece a mesquinhez da condição humana na terra, ele pôs ao lado da dor a alegria. Não como um contraste, porém, como uma fusão (Andrade, 1925 apud Miller, 1982, p. 23-4).

Como Waldemar George, Mário de Andrade traduziu o deslocamento do pintor da Alemanha para o Brasil pela passagem do trágico à alegria, expressa nas cores vibrantes e nos corpos retratados. Porém, contrariamente a George, Andrade viu no encontro de Segall com o Brasil uma síntese (aqui, entre dor e alegria), sem qualquer ironia ou, ainda menos, curiosidade divertida. Ao contrário: o que emergiu, aos olhos do crítico brasileiro, foi a "mesquinhez da condição humana" que, se não apagou, depurou, suavizou a "tragicidade" anterior. Para Mário de Andrade, não havia qualquer sacrifício de tudo pela Europa. Tratava-se mesmo do oposto: a transformação da obra de Segall tirava seu sentido da sua imersão completa no Brasil, fato impensável para George. Europeu convicto, este não tinha no horizonte, como seu colega brasileiro de profissão, a injunção nacionalista 
do modernismo, aqui projetada sobre Segall, capaz de presentear brasileiros - ou "latinos" - com sua própria "ingenuidade" esquecida.

\section{"Redenção pelo Sul"}

O entusiasmo pelo exótico amainou gradualmente em Segall, a partir do final dos anos 1920, quando estava em Paris, já dispondo de recuo espacial e temporal em relação à sua chegada ao Brasil. A paleta escureceu novamente, tornou-se mais suave, inclusive para tratar motivos brasileiros.

Tanto George quanto Andrade falaram desse retorno do pintor à Europa. Para o último, que seguia nisso a crítica alemã do imediato pós-Primeira Guerra, a essência irredutivelmente judaica de Segall, com o espiritualismo que lhe parecia próprio, estava na base da mudança acontecida durante sua fase parisiense: tratava-se, a seus olhos, de uma volta às origens.

No entanto, tal retorno não apagara a experiência brasileira, definitivamente enraizada na obra do artista. Pois o Brasil foi, para Mário de Andrade, o lugar onde Segall "descobriu a verdade"; ele pôde, a partir daí, "humanizar suas criaturas" (Andrade, 1933) ${ }^{15}$. A volta às origens, por seu lado, traduziu-se, nessa evolução, pelo abandono definitivo da tristeza em benefício não da alegria, que lhe era complementar, mas sim de uma paz, de uma nova suavidade, que o escritor identificou na produção parisiense do artista:

Si a côr se despoja daquella exterioridade luminosa da fase brasileira, os cinzas, os terras adquirem compensadoramente uma variedade, uma profundeza, uma riqueza de tons apaixonada. Se está em pleno extase. E si as figuras se conservam intensamente vivendo, não lhes succederá mais qualquer asperidade ou tristeza, calmas, "nem alegres nem tristes" (Andrade, 1933).

George também meditou sobre a maturidade do artista, que ele via alcançar a "universalidade" com a qual Andrade sonhava tão profundamente. Só que para George, como vimos, a chave encontrava-se na Europa, e

${ }^{15}$ Artigo publicado por ocasião de exposição coletiva promovida pela Sociedade Pró-Arte Moderna (SPAM), que Segall passou a dirigir logo após sua volta ao Brasil. Autor do prefácio do catálogo, Mário de Andrade sentiu a necessidade de escrever outro texto, exclusivamente dedicado ao artista. 
não no Brasil: as "normas europeias [seriam] as únicas [...] garantia[s] de universalidade" (George, 1931, p. 19). A aspiração primeira de Segall, de conquistar uma expressão artística universal, para a qual sua "natureza" de judeu seria um facilitador, apareceu, na pena de cada um dos dois críticos, conjugada segundo seus próprios horizontes, segundo o lugar respectivo de suas falas, cruzando diferentemente o périplo do artista.

Isso dito, a longa estadia em Paris teve um significado nada desprezível no percurso pessoal e profissional do pintor: entre volta à Europa, recuo em relação ao entusiasmo pelos trópicos e último longo deslocamento transatlântico, que precedeu de perto a ascensão do nazismo e o exílio definitivo no Brasil. Sem contar o surgimento de novos motivos pictóricos, como veremos, conectados com esse ponto de não retorno.

Assim, se em Paris Segall continuou a trabalhar com motivos brasileiros, como na série "Mangue", retratando essa zona de prostituição carioca que conhecera antes, com personagens negras, em que a influência da estatuária africana também se fez sentir, outras temáticas, menos "brasileiras", passaram a ocupar suas mãos. É o caso da série "Emigrantes". Aqui, Segall passou a representar a travessia do Atlântico de navio, com personagens que poderiam bem ser os judeus russos que viu chegar na Alemanha anos antes, ou voltar a partir em seguida, em direção às Américas. O tema estava em pauta nessa virada dos anos de 1920-30 e a volta à Europa reaproximou o pintor dessa realidade.

Nos anos 1939-41, vivendo em São Paulo, o tema da travessia marítima dos imigrantes fechar-se-ia com o grandioso "Navio de Emigrantes". Ironicamente, foram esses, de fato, os últimos anos em que os judeus europeus em fuga conseguiram deixar o Reich, e a Europa ocupada, e atravessar o Atlântico em busca de refúgio. Não somente a guerra no Atlântico tornou as travessias perigosas e cada vez mais raras, mas a política nazista de promover uma Europa livre de judeus empurrando-os a partir foi substituída, em outubro de 1941, pela política genocida e o fechamento das fronteiras para os judeus. Os "emigrantes" de Segall, nas gravuras executadas em Paris, ou no grande óleo em três painéis justapostos, assemelhavam-se tanto aos emigrantes que pôde ter observado anteriormente na Alemanha, 
quanto a esses refugiados que, de seu refúgio brasileiro, a partir de 1932, passou a imaginar, com a progressiva degradação da situação europeia. Contudo, como ele mesmo afirmou, não se tratava de "documento", mas de "símbolo" (Jurandir, 1943). O que alarga ainda mais os horizontes, abarcando outros povos, outras travessias, outras migrações que o artista viu, viveu e representou, em testemunho de seu tempo. Pois o que teria marcado com mais força a Europa e as Américas da virada dos séculos XIX-XX do que as migrações transatlânticas magnificadas por Segall em vida e obra?

A partida de Segall para o Brasil impediu Waldemar George de continuar a seguir seu trabalho. Mas, em 1938, o pintor representou o Brasil no Congresso Internacional de Artistas Independentes em Paris, e a galeria parisiense Renou et Colle dedicou-Ihe uma exposição individual. Nessa ocasião, o historiador e crítico de arte Paulo Fierens (1895-1957), que já havia prefaciado o catálogo de sua primeira exposição em Paris, escreveu uma monografia sobre o pintor na qual, entre outras coisas, afirmou: "[Segall] nada sacrificou ao pitoresco" (Fierens, 1938, p. 8) ${ }^{16}$.

Com o recuo que o tempo lhe dera, Mário de Andrade pôde discordar. Em 1943, por ocasião da grande retrospectiva de Segall no Ministério da Educação, o escritor debruçou-se novamente sobre a obra do artista, retraçando os caminhos percorridos até sua produção mais recente. E citou Fierens, para marcar seu desacordo. Se não citou diretamente George, distanciou-se dele também, indicando como o pintor, chegando ao Brasil, teria perdido o controle da situação diante dos apelos do exotismo:

O momento mais curioso da experiência artística de Lasar Segall foi a aventura brasileira. Não há dúvida que a participação do Brasil na obra do pintor é de importância grande. Direi mesmo que decisória, pois ainda foi auscultando a vida brasileira (a fase paisagística de Campos do Jordão) que Lasar Segall pôde melhormente definir e exercitar a sua qualidade plástica e alcançar a plenitude da fase atual. Mas na realidade o encontro do pintor com a terra do Brasil, em 1923, foi um choque violento e desnorteador. A terra se mostrou por demais cruel para com o Europeu que se entregara a ela, e como a fêmea do louva-a-deus devora o macho, pretendeu devorá-lo também.

${ }^{16}$ Este texto foi reproduzido em um número especial da Revista Acadêmica dedicado a Lasar Segall (Rio de Janeiro, ano 10, n. 64, junho de 1944). 
Assim pensando, não posso concordar inteiramente com os intérpretes de Lasar Segall que vêm na evolução do artista um progresso ininterrupto, um ritmo ascendente interior sem desfalecimento [...]. Talvez mesmo seja um bocado fácil [...] afirmar [...] que, chegando ao Brasil e feito Brasileiro, Lasar Segall "nada sacrificou ao pitoresco". Assim compreende Paul Fierens, e apenas nisso discordo dele [...]. Agora que os anos passaram, a distância revela outro sentido nos fatos. A minha interpretação é bem outra (Andrade, 1984, p. 35).

A descoberta das colinas de Campos do Jordão tornou-se, aqui, um momento decisivo, marcando o arrefecimento dos excessos "pitorescos" dos primeiros anos brasileiros. Segall deparou-se, em 1935, com essa estação de vilegiatura sofisticada, frequentada pelas elites paulistas, com seu clima seco e suas florestas de coníferas. $\mathrm{O}$ artista se apaixonou pela localidade e começou a pintar paisagens com relevos arredondados, povoadas por rebanhos, especialmente gado. A vegetação tropical luxuriante de dez anos antes cedeu então lugar a esta, igualmente brasileira, mas bem menos "típica", na qual o artista, definitivamente fixado nos trópicos, encontrou elementos perdidos de suas raízes europeias ${ }^{17}$. Na tristeza silenciosa e talvez resignada dos rebanhos de Campos do Jordão, Segall pôde se reencontrar em seu exílio tropical. Depois do arrefecimento das cores puras e contrastantes, em benefício de uma paleta menos vibrante, os motivos brasileiros que o pintor elegera nos anos de 1920 - e que eram facilmente identificáveis como "tropicais" na Europa, durante suas viagens e exposições na Alemanha e na França - deram-se também por vencidos.

Nessas colinas suaves de Campos do Jordão, Mário de Andrade identificou não somente o momento em que o artista teria atingido a universalidade tão procurada, mas também a universalidade oculta do Brasil, que assim/enfim revelou.

17 "Esse lugar maravilhoso me lembra a Suíça". Carta (em alemão) de Lasar Segall a Stefan Zweig, 27 dez.1940 (acervo Arquivo Lasar Segall). Tradução em português: Schwartz et al. (2008, p. 29). 


\section{Do Brasil para o mundo, e volta}

Apesar do desejo de Segall de instalar-se novamente na Europa e dos elogios tecidos por Waldemar George e, na mesma linha, alguns anos depois, por Paul Fierens, o artista voltou ao Brasil com a família, e em boa hora. Se já em 1923, quando deixara a Alemanha, o nacionalismo crescente tomava cada vez mais um tom xenófobo e antissemita, sua decisão de retornar ao Brasil, em 1932, foi ainda mais providencial, ainda que as razões que embasaram sua decisão fossem bem outras.

A partir de meados dos anos 1930, quando as paisagens de Campos do Jordão vieram substituir definitivamente motivos "pitorescos", Segall voltou novamente seus olhos para a Europa e retomou temáticas sociais, especialmente o destino dos judeus. Ele então produziu quadros pungentes, como "Pogrom" (1936-37) e, um pouco mais tarde, "Guerra" (1942), além dos cadernos "Visões de guerra" (1940-43), "Sobreviventes" (1946), "Êxodo" (1947, 1949), entre outros. Definitivamente instalado perto dos rebanhos de Campos do Jordão, dessas colinas suaves, silenciosas e temperadas, que o pintor estilizou cada vez mais, seu périplo terminou, mas os espaços distantes não cessaram de inspirar sua pintura, atravessada por suas migrações sucessivas. Sob o sol dessa periferia que se tornou para ele um exílio tranquilo, sobre o qual descobriu segredos menos visíveis, menos evidentes, o pintor de Vilna representou não somente o oceano atravessado por migrantes e refugiados, mas também a terra firme e devastada do Velho Continente tomado pela barbárie.

Definitivamente enraizado no Brasil, Segall foi logo esquecido na Alemanha, onde 11 de suas obras fizeram parte, em 1937, da Exposição de Arte Degenerada organizada pelos nazistas em Munique. E tantas outras, pertencentes às coleções de museus públicos alemães, foram confiscadas, muitas delas permanecendo desaparecidas até hoje. Depois da guerra, entre 1958 e 1962, uma exposição retrospectiva de sua obra circulou por várias cidades europeias, incluindo a $29^{a}$ Bienal de Veneza (1958), e o Museu Nacional de Arte Moderna de Paris (1959). Falecendo em 1957, Segall não as viu. 
Durante o percurso extremamente movimentado que tracei nessas páginas, Segall viajou inúmeras vezes, por terra, dentro da Europa, e por mar, através do Atlântico, carregando bagagens acumuladas em cada uma das margens, para a outra. Emigrou temporária e definitivamente, acabou se refugiando. Nesse périplo, viu e retratou tantos outros deslocamentos, especialmente de judeus, em um período de cerca de três décadas, em que essas migrações foram massivas, provocadas por diversas formas de perseguição.

Contudo, em seu exílio brasileiro, Segall não se limitou a retratar os dramas dos judeus europeus em busca de refúgio. Se aqui encontrou de fato proteção, sua identidade judaica não deixou de fazer-se lembrar, entre vida e arte. Ao voltar da França, em 1932, foi cofundador da Sociedade Pró-Arte Moderna (SPAM), cuja direção assumiu, organizando com energia exposições, bailes e eventos. Mas sua liderança foi veladamente questionada e uma onda também velada de antissemitismo afastou-o, cerca de dois anos mais tarde (Pinheiro Filho, 2000; Miceli, 2003). Segundo Miceli, "gentios e judeus" teriam entrado em competição em relação aos elementos e índices de prestígio e de riqueza os mais variados: propriedades, mulheres, obras de arte, relações, entre outros (2003, p. 192-3). Mas a retirada do "grupo dos judeus" (Pinheiro Filho, 2000, p. 15), liderado por Segall, indica, a meu ver, uma desigualdade nesse embate, que precede e ultrapassa os parâmetros medidores da competição evocada. O que não se podia aceitar, no fundo, é que o embate fosse uma disputa levada a cabo de igual para igual, que "o grupo dos judeus" e seu líder pudessem mensurar-se aos demais, e mensurá-los. Veladas, e de "baixa voltagem" (Miceli, 2003, p. 193), tais expressões de antissemitismo nada tinham de excepcional, estavam, ao contrário, no ar dos tempos. E diante do contexto internacional daqueles anos, não havia de fato de que reclamar... Mas Segall, Warchavchik e outros foram claramente colocados em seus lugares: a integração desejada em meio às elites artísticas e culturais locais tinha seus limites.

Uma década mais tarde, em 1943, no momento da grande exposição retrospectiva de Segall promovida pelo Ministério Capanema, uma nova 
onda de antissemitismo deflagrou-se, desta vez de modo não velado, pela imprensa. O investimento do Estado para essa grande exposição, de um artista "estrangeiro", foi considerado ilegítimo. O contexto internacional era outro: a perseguição aos judeus europeus já era conhecida no país e o Brasil encontrava-se em guerra ao lado dos Aliados, contra o nazifascismo. Declarações abertas de antissemitismo não somente contradiziam o modo habitualmente velado da expressão desse e de outros preconceitos no Brasil, como feriam o patriotismo particularmente sensível em contexto de guerra. Foi assim que inúmeras vozes se levantaram, também na imprensa, para defender Lasar Segall, sua brasilidade, considerada inegável, nacionalizando-o ${ }^{\mathbf{1 8}}$. As vozes dissidentes, minoritárias, foram caladas e a exposição aconteceu, honrando o pintor de Vilna e incorporando-o definitivamente ao patrimônio artístico do país. Ele aqui aportara em boa hora, para todos.

${ }^{18}$ Dentre os nomes que assinaram artigos em sua defesa encontravam-se Jorge Amado (O Imparcial, Salvador, 16 maio 1943), Vinícius de Moraes (A Manhã, Rio de Janeiro, 2 jun.1943), José Lins do Rego (Folha da Noite, Rio de Janeiro, 19 jun.1943), entre outros. Ver Miller (1982). 
Mônica Raisa Schpun é Pesquisadora do Centre de Recherches sur le Brésil Contemporain da EHESS, Paris, e Diretora editorial da revista Brésil(s). Sciences humaines et sociales e Professora visitante da FAU-USP, bolsista do programa USP/CAPES.

$\equiv$ moschpun@ehess.fr

\section{Referências}

1. AMARAL, Aracy A. Tarsila: sua obra e seu tempo. São Paulo: Perspectiva, 1975. 2. ANDRADE, Mário de. Pintura: Lasar Segall. A idéia, São Paulo, n. 19, 1924.

3. ANDRADE, Mário de. Lasar Segall. Diário de São Paulo, São Paulo, 6 jun.1933. 4. ANDRADE, Mário de. Lasar Segall. In: ANDRADE, Mário de. Aspectos das artes plásticas no Brasil. Belo Horizonte: Itatiaia, 1984.

5. BECCARI, Vera d'Horta. Lasar Segall e o modernismo paulista. São Paulo: Brasiliense, 1984.

6. CAIRES, Daniel R. Lasar Segall e a perseguição ao Modernismo: arte degenerada na Alemanha e no Brasil. 2018. Dissertação (Mestrado em História) - Faculdade de Filosofia, Letras e Ciências Humanas, Unniversidade de São Paulo, São Paulo, 2018.

7. CHEVREFILS DESBIOLLES, Yves. Le critique d'art Waldemar-George. Les paradoxes d'un non-conformiste. Archives Juives, v. 41, n. 2, p. 101-17, 2008. Disponível em: <https://www.cairn.info/revue-archives-juives1-2008-2page-101.htm $>$.

8. D'ALLESSANDRO, Stephanie et al. Lasar Segall: nouveaux mondes. Paris: MAHJ, 2000.

9. ELON, Amos. The pity of it all: a portrait of the GermanJewish epoch, 17431933. Nova York: Picador, 2002.

10. FIERENS, Paul. Lasar Segall. Paris: Éditions des Chroniques du jour, 1938.

11. GEORGE, Waldemar. Lasar Segall. Paris: Le Triangle, 1931.

12. GOUZI, Christine. Migrations et identités artistiques. Encyclopédie pour une histoire nouvelle de I'Europe, 2016. Disponível em: <https://ehne.fr/ node/135>.

13. JOHNSON, Val Marie. Protection, virtue, and the "power to detain": the moral citizenship of Jewish women in New York City, 18901920. Journal of Urban History, v. 31, n. 5, p. 65584, jul. 2005.

14. JURANDIR, Dalcídio. Segall, a arte pura e o homem do povo. Diretrizes, n. 48, 10 jun. 1943.

15. LE FOLL, Claire. L'école artistique de Vitebsk (1897-1923): éveil et rayonnement autour de Pen, Chagall et Malévitch. Paris: L'Harmattan, 2002. 
16. LOPEZ, Telê A. Uma difícil conjugação. In: ANDRADE, Mário de. Amar, verbo intransitivo. Belo Horizonte: Itatiaia, 1991, p. 5-40.

17. MATTOS, Claudia V. de. Lasar Segall. São Paulo: Edusp, 1997.

18. MATTOS, Claudia V. de. Lasar Segall: expressionismo e judaísmo. São Paulo: Perspectiva, 2000.

19. MATTOS, Claudia V. de. Lasar Segall e as vanguardas judaicas na Europa e no Brasil. Revista de história da arte e arqueologia, n. 7, p. 83-97, jan.-jun. 2007.

20. MICELI, Sergio. Nacional estrangeiro: história social e cultural do modernismo artístico em São Paulo. São Paulo: Companhia das Letras, 2003.

21. MILLER, Ábílio Á. et al. Lasar Segall: antologia de textos nacionais sobre a obra e o artista. Rio de Janeiro: Funarte/Instituto Nacional de Artes Plásticas, 1982.

22. PINHEIRO FILHO, Fernando A. Lasar Segall e os Antecedentes da SPAM: Os Anos 20. Anais do XXIV Encontro Nacional da ANPOCS. Petrópolis, 2000. Disponível em: <http://www.anpocs.com/index.php/encontros/papers/24encontro-anual-da-anpocs/gt-22/gt10-16/4805-fpinheiro-lasar-segall/file $>$.

23. SCHMIDT, Paul F.; SEGALL, Lasar. Lasar Segall: Gemälde und Graphik. Ausstellung 1926. Berlim: Kunstarchiv, 1926.

24. SCHNIEDEWIND, Karen. Migrants returning to Bremen: social structure and motivations, 1850 to 1914. Journal of American Ethnic History, n. 12, p. 3555, 1993.

25. SCHOLEM, Gershom. De Berlim a Jerusalém: recordações da juventude. São Paulo: Perspectiva, 1991.

26. SCHPUN, Mônica R. Justa - Aracy de Carvalho e o resgate de judeus: trocando a Alemanha nazista pelo Brasil. Rio de Janeiro: Civilização Brasileira, 2011.

27. SCHPUN, Mônica R. L'universel et l'exotique chez Lasar Segall: les avatars d'un peintre voyageur. In: DULPHY, Anne et. al. (Org.). Intellectuels, artistes et militants. Le voyage comme expérience de l'étranger. Bruxelas: Peter Lang, 2009, p. 21530.

28. SCHWARTZ, Jorge et. al. Navio de Emigrantes. São Paulo: Museu Lasar Segall/Imprensa Oficial do Estado de São Paulo, 2008.

29. SORJ, Bernardo. Sociabilidade brasileira e identidade judaica. In: SORJ, Bila (Org.). Identidades judaicas no Brasil contemporâneo. Rio de Janeiro: Imago, 1997, p. 9-31.

Recebido: 09 maio 2018

Aceito: 14 set. 2018 


\section{ERRATA}

Errata ao artigo: SCHPUN, Mônica Raisa. Lasar Segall entre viagens e migrações: um europeu nos trópicos. Sociologias, Porto Alegre, v. 20, n. 49, p. 230-256. doi 10.1590/15174522-02004907

Afiliação da autora, p. 230:

\section{Onde se lia:}

Mônica Raisa Schpun*

* Centre de recherches sur le Brésil colonial et contemporain/Mondes américains - EHESS, Paris, França.

\section{Leia-se:}

Mônica Raisa Schpun***

* Centre de recherches sur le Brésil colonial et contemporain/Mondes américains - EHESS, Paris, França / ** Faculdade de Arquitetura e Urbanismo - Universidade de São Paulo, São Paulo-SP, Brasil.

Nota sobre autora, p. 255:

\section{Onde se lia:}

Mônica Raisa Schpun é Pesquisadora do Centre de Recherches sur le Brésil Contemporain da EHESS, Paris, e Diretora editorial da revista Brésil(s). Sciences humaines et sociales

$\equiv$ moschpun@ehess.fr

\section{Leia-se:}

Mônica Raisa Schpun é Pesquisadora do Centre de Recherches sur le Brésil Contemporain da EHESS, Paris, e Diretora editorial da revista Brésil(s). Sciences humaines et sociales e Professora visitante da FAU-USP, bolsista do programa USP/CAPES.

$\equiv$ moschpun@ehess.fr 